\title{
Kardiyovasküler Hastalıklar Risk Faktörlerinden Korunmada Hemşirenin Rolü
}

Azime KARAKOÇ KUMSAR ${ }^{1}$, Feride TAŞKIN YILMAZ²

Öz

Kardiyovasküler hastalıklar tüm dünyada en önemli sağlık sorunlarından biri olup çoğu ülkede mortalite ve morbidite nedenleri arasında ilk sıralarda yer almaktadır. Irk, yaş, cinsiyet ve aile öyküsü kardiyovasküler hastalıklarda değiştirilemez risk faktörlerini oluştururken; hipertansiyon, DM, hiperlipidemi, sigara-alkol kullanımı ve obezite değiştirilebilir risk faktörleri arasında incelenmektedir. Sağlıklı beslenme, düzenli fiziksel aktivite, etkin stres yönetimi, sigara kullanmama, hijyenik önlemler ve kendi sağlik sorumluluğunu alabilme olarak tanımlanan sağlıklı yaşam biçimi davranışları, kardiyovasküler hastalık riskini düşürmektedir. Sağlıklı yaşam biçimi davranışlarının benimsenmesi ve önlenebilir risk faktörlerinin kontrolü açısından sağlık profesyonellerine, özellikle hemşirelere önemli roller düşmektedir. Bu derlemede, kardiyovasküler hastalıklarda risk faktörleri, risk faktörlerinden korunmaya yönelik sağlıklı yaşam biçimi davranışı kazandırma ve sürdürmede hemşirenin rolleri irdelenmiştir.

Anahtar Kelimeler: Kardiyovasküler hastalıklar, Risk faktörleri, Korunma, Hemşire
Yayın Bilgisi

Gönderi Tarihi:13.09.2017

Kabul Tarihi:09.11.2017

Online Yayın Tarihi: 31.12.2017

DOI: 10.26453 /otjhs.338014

Sorumlu Yazar

Feride TAŞKIN YILMAZ

\section{The role of nurses in the prevention of cardiovascular risk factors} Azime KARAKOÇ KUMSAR' ${ }^{1}$, Feride TAŞKIN YILMAZ²

\begin{abstract}
Cardiovascular diseases are the causes of mortality and morbidity in the first ranks one of the major health problems in many countries all over the world. Race, age, gender and family history of cardiovascular disease are nonmodifiable risks factors. The majority of known risk factors for these diseases are modifiable by risk factors as hypertension, diabetes, hyperlipidaemia, smoking and alcohol use and obesity. Preventive measures as healthy diet, regular physical activity, effective stress management, non-use smoking and alcohol, hygienic measures and take responsibility for their own health are defined as healthy lifestyle may reduce the risk of cardiovascular diseases. In these direction health professionals especially nurses have an important role about control of preventable risk factors. Risk factors for cardiovascular disease, roles of the nurse about risk factors preventive strategies to gain and maintain healthy life-style behaviors were examined in this review article.
\end{abstract}

Keywords: Cardiovascular diseases, Risk factors, Prevention, Nursing
Article Info

Received:13.09.2017

Accepted:09.11.2017

Online Published: 31.12.2017

DOI: $10.26453 /$ otjhs.338014

Corresponding Author

Feride TAȘKIN YILMAZ

\footnotetext{
${ }^{1}$ Biruni Üniversitesi Sağlık Bilimleri Fakültesi, İstanbul

${ }^{2}$ Cumhuriyet Üniversitesi Suşehri Sağlık Yüksekokulu, Sivas
}

\section{GíRIŞ}

Kardiyovasküler Hastalıklar (KVH) tüm dünyada en önemli sağlık sorunlarından biri olup; Dünya Sağlık Örgütü (DSÖ) 2014 raporuna göre, mortalite ve morbidite nedenleri arasında ilk siralarda yer almaktadır. ${ }^{1}$ Ülkemizde yapılan Türk Erişkinlerinde Kalp Hastalıkları ve Risk Faktörleri (TEKHARF) çalıșmasının 1990-2008 yıllarını kapsayan 2009 raporuna göre ise, 45-74 yaş aralığında koroner arter hastalığg (KAH)'na bağlı ölümler bin kişiyılında erkeklerde 7.64, kadınlarda 3.84 oranında tespit edilmiş olup; bu oranın 30 Avrupa ülkesi içinde en yüksek seviyede olduğu belirlenmiștir. $^{2}$ Önümüzdeki 10 yılda ise, koroner arter hastası sayısının iki kat artış göstereceği beklenmektedir. ${ }^{3}$ 
Birçok Avrupa ülkesinde yaşa özgül kardiyovasküler mortalite oranlarının azalmasına karşın, KVH'a sahip olan hasta sayısında artış olmaktadır. Bu durum, hastalar üzerinde yarattığ bozuklukların yanı sıra, sağlık sistemi üzerinde maliyet artışına neden olmaktadır. ${ }^{4}$

Türkiye de dahil Avrupa'da 22 ülkenin katılımıyla 2006-2007 yıllarında, KAH'nda risk faktörlerini, yaşam tarzı ve ilaç tedavilerinin kullanımını ve yeni kılavuzlara uyumu belirlemek ve zaman içindeki değiş̧imi görmek amacıyla, 76 merkezde gerçekleştirilen EUROASPIRE (European Action on Secondary and Primary Prevention by Intervention to Reduce Events) III çalışmasının Türkiye kolunun verileri, Avrupa'ya benzer şekilde, kardiyovasküler korunma hedeflerinin gerisinde kaldığını göstermiştir. Avrupa ile kıyaslandığında gözlenen en önemli farklılıkların; miyokard infarktüslü genç hasta oranının ( $<50$ yaş $)$, sigaraya devam etme durumunun (\%23.1), hareketsizlik oranlarının (\%50.2), düşük HDL-kolesterol düzeylerinin (\%36.7), tanı sonrasında hekim tarafindan izlem olmamasının (\%12) ve eğitilmeme oranlarının daha yüksek olması olarak vurgulanmıştır. ${ }^{5}$

$\mathrm{Bu}$ derleme, kardiyovasküler hastalıklarda risk faktörleri, risk faktörlerinden korunmaya yönelik sağlıklı yaşam biçimi davranışı kazandırma ve sürdürmede hemşirenin rollerini incelemek amacıyla yapılmıştır.

\section{Kardiyovasküler Hastalıklar Risk Faktörleri}

Kardiyovasküler hastalıklar risk faktörleri değiștirilebilir ve değiştirilemez faktörler olarak iki bașlık altında ele alınmaktadır (Tablo 1). ${ }^{6,7}$ $\mathrm{Bu}$ risk faktörleri yönünden bireylerin tanılanması ve gerekli önlemlerin alınması KVH'lardan korunma açısından önemlidir. ${ }^{8}$

Tablo 1. Kardiyovasküler hastalıklar risk

\section{faktörleri}

\begin{tabular}{|c|c|}
\hline Değiştirilemez risk faktörleri & Değiştirilebilir risk faktörleri \\
\hline $\begin{array}{l}\text { - Yaş } \\
\text { - Cinsiyet } \\
\text { - Birinci derece akrabalarda } \\
\text { koroner arter hastalığı } \\
\text { öyküsünün bulunması }\end{array}$ & $\begin{array}{l}\text { - Diabetes mellitus ve kötü kan } \\
\text { şekeri regülasyonu } \\
\text { - Sigara kullanımı } \\
\text { - Hipertansiyon } \\
\text { - Dislipidemi } \\
\text { - Obezite veya viseral yağlanma } \\
\text { - Psikososyal faktörler } \\
\text { - Sedanter yaşam, fiziksel } \\
\text { aktivitenin az olması } \\
\text { - Meyve ve sebze tuketiminin az } \\
\text { olması } \\
\text { - Duzenli alkol kullanımı }\end{array}$ \\
\hline
\end{tabular}

\section{Hipertansiyon}

Kan basincinda artma olarak tanımlanan hipertansiyon; KVH'ların patogenezinde önemli bir role sahip olan, büyük ölçüde değiștirilebilir risk faktörlerindendir. ${ }^{9}{ }^{10}$ Hipertansiyonun aşırı tuz tüketimi, fiziksel aktivite düzeyinin düşük olması ve psikososyal stres gibi yaşam tarzı alışkanlıkları ile de ilişkili olduğu belirtilmektedir. ${ }^{9}$

Hipertansiyon Amerika Birleşik Devletleri'nde yaklaşık 50 milyon, tüm dünyada ise yaklaşık bir milyar insanı etkilemektedir. ${ }^{10}$ Ülkemizde TEKHARF çalışması verilerine göre 
hipertansiyon sıklığ1 \%33.7 olup, bu oran 2007 2008 kohortunda erkeklerde \%37.7, kadınlarda \%46.3 olarak saptanmıştır. ${ }^{11} 20$ yaş üzeri 4259 bireyin katılımı ile gerçekleştirilen Türkiye Metabolik Sendrom Araştırması (METSAR) raporunda ise hipertansiyon prevalansı \%55.7 olarak bulunmuştur. ${ }^{12}$

\section{Tip 2 Diabetes Mellitus}

Diyabetes mellitus (DM), tüm dünyada obezitenin artmasina paralel olarak ciddi bir artış göstererek, devam eden bir epidemi haline gelmiştir. ${ }^{11}$ Tip 2 DM, insülin direncini takiben ortaya çıkan bir tablo olup yağ dokusu artışı ve yağ metabolizması bozukluğu ile yakın ilişkili bir hastalıktır. ${ }^{13}$ DM sıklığı TURDEP-I sonuçlarına göre 20 yaş ve üzeri erişkin erkeklerde $\% 6.2$, kadınlarda $\% 8$ (genel ortalama \%7.2) iken, TURDEP-II sonuçlarına göre genel ortalama \%13.7 (erkek \%12.4 ve kadın \%14.6) olarak saptanmış ve 12 yıllık zaman içinde ciddi bir artış meydana geldiği belirlenmiştir. ${ }^{14}$ Tip 2 DM olan bireyin, olmayana göre KVH gelişimi açısından 3.2 kat daha fazla risk altında olduğu belirtilmektedir. ${ }^{15}$ Ayrıca, tüm DM olan hasta ölümlerinin \%70-80'inden KVH sorumlu olup, ölümlerin dörtte üçünün KAH'a bağlı olduğu ifade edilmektedir. DM ve insülin direnci sıklıkla eşlik eden hiperlipidemi, hipertansiyon ve obezite gibi diğer kardiyovasküler risk faktörlerinin de hızlanmıș ateroskleroz ve bunun sonucunda artmış $\mathrm{KVH}$ riski artışına neden olduğu belirtilmektedir. ${ }^{16}$

\section{Dislipidemi}

Dislipidemi, KAH risk faktörleri arasında önemli bir yer tutmaktadır. ${ }^{7}{ }^{17}$ İnsülin direnci ve abdominal obezite sonucu gelişen dislipidemi, HDL-K düşüklüğü ve trigliserid yüksekliği ile tanımlanmaktadır. ${ }^{9}$

Ülkemizde TEKHARF 1990 ilk taramasında, 35-64 yaş grubunda ortalama total kolesterol düzeyi erkeklerde 185 mg/dl ve kadınlarda 192 mg/dl olarak belirlenmiş olup; 2001/2002 yılı taramasında erkeklerde 186 mg/dl ve kadınlarda $195 \mathrm{mg} / \mathrm{dl}$ ortalama total kolesterol düzeyi saptanmıştır. ${ }^{18}$ Ülkemizde metabolik sendrom sıklığını belirlemek amacıyla büyük bir kesimi kapsayan METSAR çalışma sonuçları da benzer olup, ortalama total kolesterol düzeyi erkeklerde $173.6 \mathrm{mg} / \mathrm{dl}$, kadınlarda $179.6 \mathrm{mg} / \mathrm{dl}$ olarak bulunmuştur. METSAR sonuçlarına göre, trigliserid ortalama düzeyi erkeklerde 148.3 mg/dl, kadınlarda 129.7 mg/dl' dir. ${ }^{12}$

Ülkemizde HDL-kolesterol düşüklügüü tartışmalı bir konu olmakla birlikte, yapılan çalışmalarda farklılık gözlenmektedir. EUROASPIRE III Türkiye sonuçları Avrupa verileri ile karşılaştırıldığında, total kolesterol ve trigliserid yüksekliği oranlarının benzer olduğu saptanırken, HDL-kolesterol düşüklügü önemli derece yüksek izlenmiştir. Ortalama HDLkolesterol düzeyi kadınlarda $46 \mathrm{mg} / \mathrm{dl}$ ve erkeklerde $39.4 \mathrm{mg} / \mathrm{dl}$ olarak verilmiştir. ${ }^{5}$ 
Obezite

Obezite, DSÖ tarafından, sağlığı bozacak ölçüde vücutta anormal ya da aşırı yağ birikmesi olarak tanımlanmaktadır. DSÖ verilerine göre, 2014 yllında 18 yaşı üzerinde bireylerin \%39'u fazla kilolu ve \%13'ü obezdir. ${ }^{19}$ Ülkemizde TURDEP I çalışması sonuçlarına göre 20 yaş ve üzerindeki bireylerde obezite sıklığı \%22, santral obezite $\% 34.3$ olup; kadınlarda $\% 48.4$ ve erkeklerde \%16.9 olarak tespit edilmiştir. ${ }^{14}$ Obezite sıklığı on iki yıl içinde $\% 44$ oranında, obezite $\% 35$ oranında artmış, kadınlarda kilo 6 $\mathrm{kg}$, bel çevresi $6 \mathrm{~cm}$, kalça çevresi $7 \mathrm{~cm}$, erkeklerde kilo $8 \mathrm{~kg}$, bel çevresi $7 \mathrm{~cm}$, kalça çevresi $2 \mathrm{~cm}$ artmıştır. ${ }^{20}$ METSAR verilerine göre de obezite sıklığı erkeklerde \%20.6 ve kadınlarda \%39.9 olmak üzere; genel ortalamada $\% 30.3$ oranındadır. ${ }^{12}$

Günümüzde intraabdominal yağ dokusunun belirlenmesinde kullanılan bel çevresi (BÇ) değerinin, beden kitle indeksi (BKİ) değerinden daha geçerli olduğu ifade edilmektedir. ${ }^{21} \mathrm{Bel}$ çevresi kalınlığı, intraabdominal organların etrafinda bulunan yağ dokusundaki artışın objektif bir göstergesidir. ${ }^{13}$, 22 Sadece obez bireylerin değil normal ya da fazla kilolu bireylerin de $\mathrm{BÇ}$ ölçümü, kardiyometabolik risk taşıyan bireyleri erken saptamak adına etkin bir yöntemdir. ${ }^{22}$ Abdominal obezitede $\mathrm{BÇ}$ sınır değeri, Uluslararası Diyabet Federasyonu'nun 2005 k1lavuzunda, Avrupalılar için önerilen değerleri temel alındığı, kadınlar için $>80 \mathrm{~cm}$ ve erkekler için $>94 \mathrm{~cm}$ olarak kabul edilmektedir. $^{23}$

\section{Hemșirenin Kardiyovasküler Risk}

\section{Faktörlerinden Korunmaya Yönelik Rolleri}

Son yıllarda KVH konusunda farkındalı̆̆ın artırılmasına yönelik çalışmaların artırılmasına rağmen, KVH halen hem gelişmiş hem de gelişmekte olan ülkelerde en önemli ölüm nedeni olarak görülmektedir. ${ }^{5,}$ Hastalık belirti bulgularının olmadığı bireylerde yaşam biçimi değişiklikleri ve risk faktörlerinin düzeltilmesiyle hastalı oluşumunun engellenmesi primer korunmay $1,{ }^{6}$ hastalık tanıs almış bireylerde hastalığın ilerlemesini önleme girişimleri de sekonder korunmayı içermektedir. ${ }^{8}$

Kardiyovasküler hastalıklardan korunmaya yönelik primer koruma, toplum sağlığ açısından oldukça önemlidir. Bu bağlamda, risk faktörlerine yönelik tarama programlarının sürdürülmesinde, risk faktörlerinin erken dönemde tespit edilmesinde ve tedaviye yönlendirilmesinde, hastalarla sürekli birlikte olan ve bakımından birinci derecede sorumlu olan hemşirelere etkin roller düşmektedir. ${ }^{24,25}$

Hemşire, yeterli sağlık öyküsü alarak ve kardiyovasküler risk faktörleri üzerine odaklanarak dikkatli bir değerlendirme ile risk altındaki bireyleri belirleyebilir. Hemşire sağlık öyküsünde bireyin öz geçmişini, aile hikayesini, yaşam şeklini ve alışkanlıklarını sorgulamalıdır. 
Hemşire özellikle bireylerin $\mathrm{KVH}$, ve danışmanlık uygulamalarını yürüterek ekip serebrovasküler hastalık, periferik arter ile sürekli işbirliği içinde olmalıdır. ${ }^{8,}{ }^{28}$ Tablo hastalığı, abdominal aort anevrizması, son evre 3'te kardiyovasküler hastalıklar risk faktörleri ya da kronik böbrek hastalığı ve DM öyküsüne kontrolüne ilişkin birey ve aile eğitiminde ve/veya mevcut belirtilerine dikkat etmelidir. Sağlık öyküsünü aldıktan sonra hemşire fiziksel muayeneye başlamalıdır. Hemşire fizik muayene yaparken, kan basıncını ölçmeli, BKI ve bel çevresini değerlendirmelidir. Aynı zamanda açlık kan şekeri, kolesterol düzeyleri gibi laboratuvar sonuçlarını incelemelidir. Anamnez ve fizik muayene tamamlandiktan sonra, hemşire hastanın risk durumunu belirlemelidir. ${ }^{26}$ Kardiyovasküler hastalık risk sınıflandırması Tablo 2'de verilmiştir. ${ }^{27}$

Tablo 2. Kardiyovasküler hastalık risk sınıflandırması

\begin{tabular}{|c|c|}
\hline Risk sinıflan & \\
\hline Düşük Risk & En fazla 2 risk faktörü varlığ 1 \\
\hline Orta Risk & $\geq 3$ risk faktörü varlığ 1 \\
\hline Yüksek Risk & $\begin{array}{l}<50 \text { yaş Metabolik sendrom } \\
\text { Aterosklerotik damar hastalığ }\end{array}$ \\
\hline & Diabetes mellitus \\
\hline & $\geq 50$ yaş Metabolik sendrom \\
\hline
\end{tabular}

Kardiyovasküler hastalık risk faktörlerinden korunma amaciyla hemşire, eğitim ve danışmanlık rollerini üstlenenerek, risk durumuna göre yaşam biçimi değişiklikleri açısından bireyi motive etmelidir. ${ }^{25} \mathrm{Bu}$ amaçla sigaranın bırakılması, sağlıklı beslenme ve düzenli fiziksel aktivite ile ideal kilonun sağlanması, etkin stres yönetimi ve düzenli sağlık kontrollerinin yapılmasına yönelik eğitim sağlığı geliştirici davranışlar gösterilmiştir. ${ }^{29}$

Tablo 3. Kardiyovasküler hastalıklar risk faktörleri kontrolüne ilișkin birey ve aile eğitimi

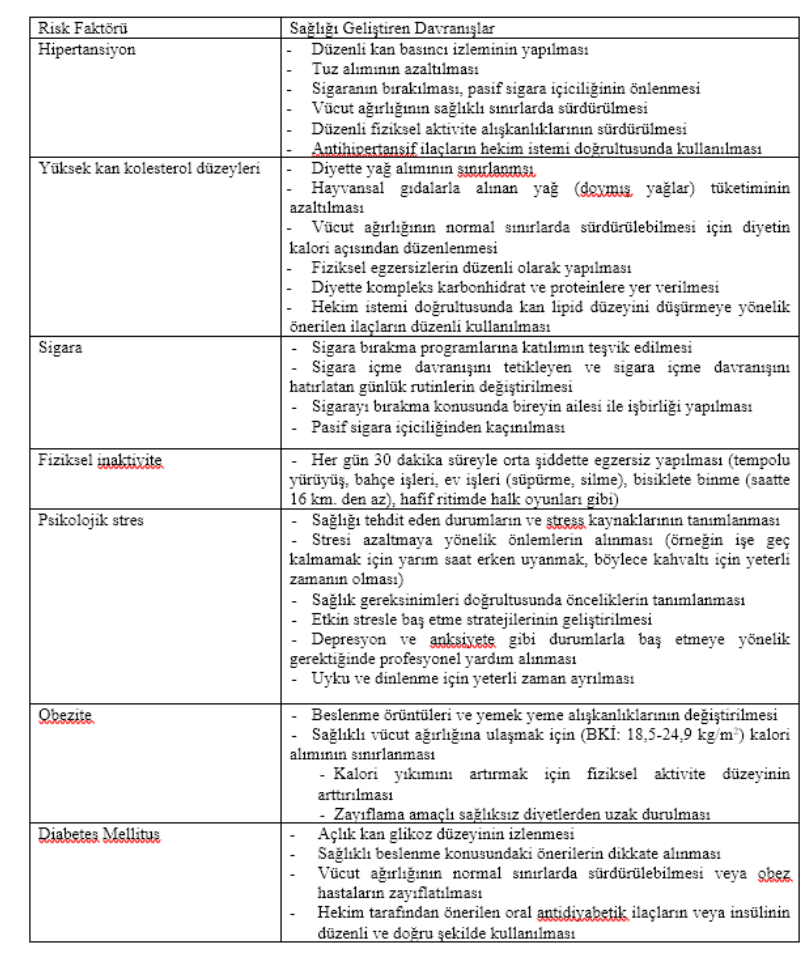

Kardiyovasküler hastalıklar risk faktörlerinden korunmaya yönelik planlanan davranış değişikliklerin ilk basamağı, bireyin mevcut durumunu anlamak ve bireyin var olan yaşam davranışı alışkanlıklarını değerlendirmek olmalıdır. Bunun için hemşirenin, bireyden bir günü hafta sonuna gelmek üzere en az üç günlük besin tüketim ve fiziksel aktivite kayıtlarını istemesi ve değerlendirmesi gerekmektedir. Böylece, hemşire bireyin olumsuz davranışlarını fark etmesini 
sağlayabilir, hedeflenen değişiklikler hakkındaki kararları birey ile birlikte alabilir. ${ }^{30}$

Kardiyovasküler hastalıklarda hem primer korunma hem de sekonder korunma aşamasında hemşirelerin önemli roller üstlendikleri ve olumlu gelişme sağladıkları literatürde yer almaktadır. ${ }^{8,25}$ Koroner arter hastalığ yüksek riskli bireylere yönelik, hemşire koordineli multidisipliner, aile temelli $\mathrm{KVH}$ önleme programı-Preventive Cardiology Programme (EUROACTION) European Society of Cardiology (ESC) tarafından geliştirilmiştir. Sekiz Avrupa ülkesinden altı çift (kontrol ve deney) hastane araştırmaya alınmıştır, bir yıl sonra tedavi edici yaşam tarzı değişikliği, kan basınc1, kan glikozu ve kolesterol kontrolü, ilaç kullanımı değerlendirilmiştir. Hastalar eğitime eşleri ile birlikte alınmış, 16 hafta sonra ilk izlem yapılmış, bir y1l sonra bireysel risk faktörleri, yaşam tarzı değişiklikleri, farmakolojik tedaviye uyum düzeylerine bakılmıştır. Sonuçta, hemşire odaklı multidisipliner bir standart yaklaşımın, sağlıklı yaşam biçimi davranışları kazanmada ve risk faktörlerinin kontrol altına alınmasında etkin olduğu saptanmıştır. ${ }^{28}$

Hasta eğitimi ve rutin izleminin hipertansiyon yönetimi, sağlıklı yaşam biçimi davranışları ve BKİ üzerine etkisini değerlendirmek üzere planlanan bir çalışmaya toplam 120 hasta alınmış olup, deney grubundaki bireylere sağlıklı yaşam biçimi davranışları ve hipertansiyon hakkında eğitim planlanarak; dördü klinikte ve ikisi evde olmak üzere hipertansiyon hastalığına, hipertansif bireylerde ilaç uyumunu artırma girişimlerine ve hipertansif bireylere sağlıklı yaşam biçimi davranışlarını öğretmeye, artırmaya ve uygulatmaya yönelik yaklaşık 30 dakika süren oturumlardan oluşan bir eğitim program uygulanmış, ek olarak bireylere her ay bireysel telefon görüşmesi ile danışmanlık verilmiştir. Çalışma sonunda, deney grubundaki hastaların kontrol grubundaki hastalara göre biyokimyasal parametre ve kan basincı ortalamasında anlamlı düşüş olduğu ve sağlıklı yaşam biçimi davranışlarında iyileşme olduğu saptanmıștır. $\mathrm{Bu}$ sonuçlar verilen hemşirelik eğitiminin sağlıklı yaşam biçimi davranışları üzerine olumlu etkileri olduğu ile ilişkilendirilmektedir. ${ }^{31}$

Ülkemiz ve yurtdışında yapılan diğer çalışma bulguları da hemşire eğitimi ve danışmanlığının sağlıklı yaşam biçimi davranışları kazanmada ve kilo kontrolünde etkin bir yöntem olduğunu destekler niteliktedir. ${ }^{32,35}$

\section{SONUÇ}

Ülkemizde diğer toplumlarda olduğu gibi KVH prevalansı gün geçtikçe artmaktadır. Bu nedenle bireylerde $\mathrm{KVH}$ risk faktörlerinin değerlendirilmesi, erken tanılanması, yerleşmiş yanlış yaşam biçimi davranışlarının saptanması ve tutumu etkileyen bireysel faktörlerin 
tanınması kardiyovasküler hastalıkların önlenmesi açısından önemlidir. Risk faktörlerinin giderilmesinde sağlıklı yaşam tarzı davranışlarının benimsenmesi ve önlenebilir risk faktörlerinin kontrolü açısından sağlık profesyonellerine, özellikle hemşirelere önemli roller düşmektedir.

\section{KAYNAKLAR}

1. World Health Organization, Global status report on noncommunicable diseases 2014.

2. Onat A, Uğur $M$, Tuncer $M$, et al. Age at death in the Turkish adult risk factor study: Temporal trend and regional distribution at 56,700 person-years' follow-up. Türk Kardiyol Dern Arş 2009;37(3):155-60.

3. Güleç S. Kalp damar hastalıklarında global risk ve hedefler. Türk Kardiyol Dern Arş 2009; 37(2):1-10.

4. Lopez AD, Mathers CD, Ezzati M, Jamison DT, Murray CJ. Global and regional burden of disease and risk factors, 2001: systematic analysis of population health data. Lancet 2006;367(9524):1747-57.

5. Tokgözoğlu L, Kaya E.B, Erol Ç, Ergene O. EUROASPIRE III: Türkiye ile Avrupa'nın karşılaştırılması. Türk Kardiyol Dern Arş 2010;38(3):164-72.

6. Türkmen, E., Güven GS. Kardiyovasküler hastalıklardan primer korunma esasları. Hacettepe Tip Dergisi 2010;41(3):179-85.
7. Şendur MAN, Güven GS. Kardiyovasküler risk modelleri; ideal bir model var mı? Hacettepe Tip Dergisi 2010;41(3):171-8.

8. Türkmen E, Badır A, Ergün A. Koroner arter hastalıkları risk faktörleri: Primer ve sekonder korumada hemşirelerin rolü. Acıbadem Üniversitesi Sağlık Bilimleri Dergisi 2012;3(4):223-31.

9. Büyüktuncer Z, Köksal G, Erbaş T. Metabolik sendrom ve diyet. Endokrinolojide Diyalog 2009;6(4):220-5.

10. Hacıhasanoğlu R. Hipertansiyonda tedaviye uyumu etkileyen faktörler. TAF Prev Med Bull 2009;8(2):167-72.

11. Wild S, Roglic G, Green A, Sicree R, King H. Global Prevalence of Diabetes. Diabetes Care 2004;27(5):1047-53

12. Kozan Ö, Oğuz A, Abac1 A, et al. Prevalence of the metabolic syndrome among Turkish adults. European Journal of Clinical Nutrition. 2007;61(4):548-553.

13. Oğuz A. Metabolik sendrom. Klinik Psikofarmakoloji Bülteni 2008;18(2):57-61.

14. Satman İ, Y1lmaz T, Sengül A, et al. and TURDEP Group. Population-based study of diabetes and risk characteristics in Turkey: Results of the Turkish diabetes epidemiology study (TURDEP). Diab Care 2002;25(9):1551-6.

15. Karmally W, Drago L, Odegard P, et al. Healthy eating: Incorporating nutritional management into lifestyle. The Tip II diabetes EDUCATOR 2012;38(1):124-8. 
16. Işı1k S, Delibaş T, Berker D, Aydın Y, Güler S. Kalp hastalıklarında diyabet yönetimi. Anadolu Kardiyol Dergisi 2009;9(1):23847.

17. Grundy SM, Cleeman JI, Merz CNB, et al. Implications of recent clinical trials for the National Cholesterol Education Program Adult Treatment Panel III Guidelines. Circulation 2004;110(2):227-39.

18. Onat A. Türk halkında lipid, lipoprotein ve apolipoproteinler. Türk halkının kusurlu kalp sağlığı: sırrına 1şık, tıbba önemli katkı. TEKHARF 2009. Editör: Onat A. İstanbul: Cortex İletişim Hizmetleri s.39-58.

19. Obesity and overweight. World Health Organization. Accessed March 18, 2017, at http://www.who.int/mediacentre/factsheets/f s311/en/

20. Satman I, Omer B, Tutuncu Y, et al. Twelve-year trends in the prevalence and risk factors of diabetes and prediabetes in Turkish adults. Eur J Epidemiol 2013;28(2):169-80.

21. Appel SJ, Jones ED, Kennedy-Malone L. Central obesity and the metabolic syndrome: Implications for primary care providers. Journal of the American Academy of Nurse Practitioners 2004; 16(8):335-342.

22. Ritchie SA, Connell JMC. The link between abdominal obesity, metabolic syndrome and cardiovascular disease. Nutrition, Metabolizm \& Cardiovascular Diseases 2007;17(4):319-26.
23. Alberti KGMM, Eckel RH, Grundy SM, et al. Harmonizing the Metabolic Syndrome. A joint Interim Statement of the International Diabetes Federation task force on epidemiology and prevention; National Heart, Lung and Blood Institute; American Heart Association; World Heart Federation; International Atherosclerosis Society and International Association for the study of obesity. Circulation 2009;120(16):1640-5.

24. Cebeci F. Kardiyovasküler hastalıklarda depresyonun önlenmesi, saptanması ve tedaviye yönlendirilmesinde hemşirenin rolü. Türkiye Klinikleri 2007;19(1):86-9.

25. Berra K, Jennings CS. Nurse-based models for cardiovascular disease prevention from research to clinical practice. Journal of Cardiovascular Nursing 2011;26(4):46-55.

26. Alkan HÖ, Enç N. Kadınlarda kardiyovasküler hastalıkların önlenmesinde hemşirenin rolü. Türk Kardiyol Dern Kardiyovasküler Hemşirelik Dergisi 2013;4(5):14-29.

27. Buğan B, Çelik T. Koroner arter hastalığ 1 risk faktörleri. J Clin Anal Med 2014;5(2):159-63.

28. Wood DA, Kotseva K, Connolly S, et al. Nurse - coordinated multidisciplinary, family - based cardiovascular disease prevention programme (EUROACTION) for patients with coronary heart disease and asymptomatic individuals at high risk of cardiovascular disease: A paired, cluster - 
randomised controlled trial. Lancet 2008;371(9629):1999-2012.

29. Akın S. Kardiyovasküler sistem hastalıkları ve bakım. İçinde: Durna Z, ed. İç Hastalıkları Hemşireliği, Akademi Basın ve Yayıncılık, İstanbul; 2013. s.197.

30. Akbulut G, Rakıcıoğlu N. Şişmanlığın beslenme tedavisinde güncel yaklaşımlar. Genel T1p Dergisi 2010;20(1):35-42 .

31. Hacıhasanoğlu R, Gözüm S. The effect of patient education and home monitoring on medication compliance, hypertension management, healthy lifestyle behaviours and BMI in a primary health care setting. Journal of Clinical Nursing 2010;20(56):692-705.

32. Y1lmaz M. Beslenme eğitiminin obez hastalarda ağırlık kaybı üzerine etkisi. Turkish Journal of Endocrinology and Metabolism 2003;7(2):83-5.
33. Silva MN, Vieira PN, Coutinho SR, et al. Using self - determination theory to promote physical activity and weight control: a randomized controlled trial in women. J Behav Med 2010;33(2):110-22.

34. Pettman TL, Buckley JD, Misan GMH, Coates AM, Howe PRC. Health benefits of a 4 - month group - based diet and lifestyle modification program for individuals with Metabolic Syndrome. Obesity Research \& Clinical Practice 2009;3(4):221-35.

35. Dutheil F, Lesourd B, Courteix D, Chapier R, Dore E, Lac G. Blood lipids and adipokines concentrations during a 6-month nutritional and physical activity intervention for Metabolic Syndrome treatment. Lipids in Health and Disease 2010;9(1):148 
Tablo 3. Kardiyovasküler hastalıklar risk faktörleri kontrolüne ilişkin birey ve aile eğitimi

\begin{tabular}{|c|c|}
\hline Risk Faktörü & Sağlığı Geliştiren Davranışlar \\
\hline Hipertansiyon & $\begin{array}{ll}\text { - } & \text { Düzenli kan basıncı izleminin yapılması } \\
\text { - } & \text { Tuz alımının azaltılması } \\
\text { - } & \text { Sigaranın bırakılması, pasif sigara içiciliğ̈inin önlenmesi } \\
\text { - } & \text { Vücut ağırlığının sağlıklı sınırlarda sürdürülmesi } \\
\text { - } & \text { Düzenli fiziksel aktivite alışkanlıklarının sürdürülmesi } \\
\text { - } & \text { Antihipertansif ilaçların hekim istemi doğrultusunda kullanılması }\end{array}$ \\
\hline Yüksek kan kolesterol düzeyleri & $\begin{array}{l}\text { - Diyette yağ alımının sınırlanmsı } \\
\text { - Hayvansal gidalarla alınan yağ (doymış yağlar) tüketiminin } \\
\text { azaltılması } \\
\text { - Vücut ağırlığının normal sınırlarda sürdürülebilmesi için diyetin } \\
\text { kalori açısından düzenlenmesi } \\
\text { - Fiziksel egzersizlerin düzenli olarak yapılması } \\
\text { - Diyette kompleks karbonhidrat ve proteinlere yer verilmesi } \\
\text { - Hekim istemi doğrultusunda kan lipid düzeyini düşürmeye yönelik } \\
\text { önerilen ilaçların düzenli kullanılması }\end{array}$ \\
\hline Sigara & $\begin{array}{l}\text { - Sigara bırakma programlarına katılımın teşvik edilmesi } \\
\text { - Sigara içme davranışını tetikleyen ve sigara içme davranışını } \\
\text { hatırlatan günlük rutinlerin değiştirilmesi } \\
\text { - Sigarayı bırakma konusunda bireyin ailesi ile işbirliği yapılması } \\
\text { - Pasif sigara içiciliğinden kaçınılması }\end{array}$ \\
\hline Fiziksel inaktivite & $\begin{array}{l}\text { - Her gün } 30 \text { dakika süreyle orta şiddette egzersiz yapılması (tempolu } \\
\text { yürüyüs, bahçe işleri, ev işleri (süpürme, silme), bisiklete binme (saatte } \\
16 \mathrm{~km} \text {. den az), hafif ritimde halk oyunları gibi) }\end{array}$ \\
\hline Psikolojik stres & $\begin{array}{l}\text { - Sağlığı tehdit eden durumların ve stress kaynaklarının tanımlanması } \\
\text { - Stresi azaltmaya yönelik önlemlerin alı̈ması (örneğin işe geç } \\
\text { kalmamak için yarım saat erken uyanmak, böylece kahvaltı için yeterli } \\
\text { zamanın olması) } \\
\text { - Sağl1k gereksinimleri doğrultusunda önceliklerin tanımlanması } \\
\text { - Etkin stresle baş etme stratejilerinin geliştirilmesi } \\
\text { - Depresyon ve anksiyete gibi durumlarla baş etmeye yönelik } \\
\text { gerektiğinde profesyonel yardım alınması } \\
\text { - Uyku ve dinlenme için yeterli zaman ayrılması }\end{array}$ \\
\hline Obezite & $\begin{array}{l}\text { - Beslenme örüntüleri ve yemek yeme alışkanlıklarının değiştirilmesi } \\
\text { - Sağl1klı vücut ağırlığına ulaşmak için (BKİ: } 18,5-24,9 \mathrm{~kg} / \mathrm{m}^{2} \text { ) kalori } \\
\text { alımının sınırlanması } \\
\text { - Kalori yıkımını artırmak için fiziksel aktivite düzeyinin } \\
\text { arttırılması } \\
\text { - Zayıflama amaçlı sağlıksız diyetlerden uzak durulması }\end{array}$ \\
\hline Diabetes Mellitus & $\begin{array}{ll}\text { - } & \text { Açlık kan glikoz düzeyinin izlenmesi } \\
\text { - } & \text { Sağlıklı beslenme konusundaki önerilerin dikkate alınması } \\
\text { - } & \text { Vücut ağılığııın normal sınırlarda sürdürülebilmesi veya obez } \\
\text { hastaların zayıflatılması } \\
\text { - } \\
\text { Hekim tarafından önerilen oral antidiyabetik ilaçların veya insülinin } \\
\text { düzenli ve doğru şekilde kullanılması }\end{array}$ \\
\hline
\end{tabular}

